\title{
PENGARUH SISTEM TANAM DAN JARAK TANAM TERHADAP DOMINASI GULMA, PERTUMBUHAN DAN HASIL PADI DI DESA DEPOK CISOMPET KABUPATEN GARUT
}

\author{
The Effect of Planting System and Plant Spacing to Weed \\ Dominance, Growth and Yield of Rice in Depok Ciompett Garut
}

\author{
Jenal Mutakin ${ }^{1)}$, Ayudita Damayanti' ${ }^{2}$, Rama Adi Pratama ${ }^{1)}$ \\ ${ }^{1)}$ Dosen Program Studi Agroteknologi Fakultas Pertanian Universitas Garut \\ ${ }^{2}$ Mahasiswa Program Studi Agroteknologi Fakultas Pertanian Universitas Garut \\ E-mail : jenalmutakinm@gmail.com
}

\begin{abstract}
ABSTRAK
Padi merupakan komoditas tanaman pangan penghasil beras yang menjadi makanan pokok lebih dari setengah penduduk dunia dan memegang peranan penting dalam kehidupan ekonomi Indonesia. Penelitian ini bertujuan untuk mengetahui pengaruh sistem tanam dan jarak tanam terhadap dominasi gulma, pertumbuhan dan hasil padi di Desa Depok Cisompet Kabupaten Garut. Penelitian dilaksanakan pada bulan Oktober 2017 sampai Februari 2018. Metode yang digunakan dalam penelitian ini adalah metode eksperimental menggunakan Rancangan Petak Terpisah (Split Plot Design) dengan faktor pertama sebagai main plot adalah sistem tanam (S) terdiri dari 3 taraf perlakuan, yaitu $: \mathrm{s}_{1}=$ Sistem Organik, $\mathrm{s}_{2}=$ Sistem Tanpa Olah Tanah (TOT), dan $\mathrm{s}_{3}=$ Sistem Konvensional, sedangkan faktor kedua sebagai sub plot adalah jarak tanam (J) terdiri dari 4 taraf perlakuan, yaitu : $\mathrm{j}_{1}=20 \times 20 \times 40 \mathrm{~cm}, \mathrm{j}_{2}$ $=30 \times 30 \times 50 \mathrm{~cm}, \mathrm{j}_{3}=25 \times 25 \mathrm{~cm}$, dan $\mathrm{j}_{4}=30 \times 30 \mathrm{~cm}$, kombinasi perlakuan sebanyak 12 yang diulang 3 kali. Hasil penelitian menunjukkan bahwa terjadi interaksi antara sistem tanam dengan jarak tanam terhadap tinggi tanaman umur 40 HST, dan tinggi tanaman umur $60 \mathrm{HST}$. Secara mandiri sistem tanam organik memberikan pengaruh terbaik terhadap jumlah anakan dan jumlah anakan produktif, sedangkan sistem konvensional memberikan pengaruh terbaik terhadap bobot gabah per rumpun dan bobot 1000 butir gabah kering panen, serta terdapat gulma dominan yang berbeda pada sistem organik dengan sistem TOT dan sistem konvensional.
\end{abstract}

Kata Kunci : Sistem Tanam, Jarak Tanam, Gulma, Oryza sativa L. 


\begin{abstract}
Rice plants is a commodity that produces rice which is the staple food for more than a half of the world's population and play an important role in Indonesia's economic life. This study aims to known about the effect of planting system and plant spacing to weed dominance, growth and yield of rice in Depok Cisompet Garut. The study was from October 2017 until February 2018. The method used in this research is experimental method used Split Plot Design with first factor as main plot was palnting system $(S)$ consisted of 3 treatments levels : $s_{1}=$ Organic system, $s_{2}=$ No tillage system, and $s_{3}=$ Conventional system, while the second factor as sub plot was plant spacing $(\mathrm{J})$ consisted of 4 treatment levels $: j_{1}=20 \times 20 \times 40 \mathrm{~cm}, j_{2}=30$ $\times 30 \times 50 \mathrm{~cm}, j_{3}=25 \times 25 \mathrm{~cm}$, and $j_{4}=30 \times 30 \mathrm{~cm}, 12$ treatment ombinations are repeated 3 times. The result showed there are interaction between planting system and plant spacing to plant height at 40 and 60 days after planting. Independtly, organic system has effect to number of tillers and number of productive tillers, while the conventional system has effect to the weight of grain perclump and the weight of 1000 grains of dry harvest, and there are different dominant weeds in organic system with no tillage system and conventional system.
\end{abstract}

Keywords : Planting system, Plant spacing, Weed, Oryza sativa L.

\title{
PENDAHULUAN
}

Tanaman padi (Oryza sativa L.) merupakan komoditas tanaman pangan penghasil beras yang menjadi makanan pokok lebih dari setengah penduduk dunia dan memegang peranan penting dalam kehidupan ekonomi Indonesia. Kebutuhan beras terus meningkat sejalan dengan peningkatan jumlah penduduk. Konsumsi beras nasional mencapai $117 \mathrm{~kg} / \mathrm{kapita} / \mathrm{tahun}$ (Kementan, 2017). Sedangkan, produksi padi nasional selama kurun waktu 10 tahun terakhir tidak menunjukkan peningkatan hasil yang berarti (Deptrina, 2008). Salah satu faktor yang menyebabkan rendahnya hasil padi baik kualitas maupun kuantitas adalah gangguan gulma. Gulma menyerap hara dan air lebih cepat dibanding tanaman pokok (Brown, 2002). Akan tetapi kemampuan bersaing suatu spesies tanaman banyak ditentukan oleh ruang yang dapat dikuasai pada awal pertumbuhannya. Salah satu faktor yang mempengaruhi periode kritis tanaman akibat persaingan gulma adalah cara budidaya tanaman (Mercado, 1979). Cara budidaya yang digunakan diantaranya menyangkut pemilihan sistem tanam dan penggunaan jarak tanam. Penggunaan sistem tanam yang berbeda pada budidaya padi akan menghasilkan jenis gulma yang berbeda pula. Hal ini sesuai dengan pendapat 
Antralina (2012) yang menyatakn bahwa jenis-jenis gulma pada tanaman padi bermacam-macam yang komposisinya berbeda menurut metode bercocok tanam, tata air dan tanah, tingkat pengolahan tanah, cara pemupukan, pergiliran tanaman, cara pengendalian, kondisi iklim, dan populasi jenis-jenis gulma yang ada serta musim tanam. Spesies gulma juga dipengaruhi oleh kerapatan tanaman, kesuburan tanah, pola budidaya dan pengolahan tanah (Aldrich, 1984). Keberadaan spesies gulma yang berbeda pada pertanaman padi akan menyebabkan kehilangan hasil padi yang berbeda. Hal tersebut dikarenakan kemampuan suatu spesies dalam bersaing mendapatkan unsur hara juga berbeda. Interaksi antara jarak tanam dan sistem tanam yang digunakan dapat berpengaruh terhadap kemampuan bersaing suatu spesies, karena jarak tanam pada sistem tanam yang berbeda dapat menentukan ruang tumbuh spesies itu sendiri dalam mendapatkan cahaya, air, dan unsur hara untuk pertumbuhannya. Oleh karena itu penelitian ini bertujuan untuk mengetahui pengaruh interaksi dari sistem tanam dan jarak tanam padi terhadap dominasi gulma, pertumbuhan dan hasil tanaman padi di desa Depok Cisompet, Kabupaten Garut.

\section{METODE PENELITIAN}

Penelitian dilaksanakan di lahan sawah Desa Depok, Kecamatan Cisompet, Kabupaten Garut dengan ketinggian tempat sekitar 110 meter diatas permukaan laut pada bulan Oktober 2017 sampai Februari 2018. Penelitian menggunakan Rancangan Petak Terpisah (RPT) pola faktorial 3x4 dan diulang sebanyak tiga kali dengan faktor pertama sebagai main plot adalah sistem tanam (S) terdiri dari 3 taraf perlakuan, yaitu $: \mathrm{s}_{1}=$ Sistem Organik, $\mathrm{s}_{2}=$ Sistem Tanpa Olah Tanah $(\mathrm{TOT})$, dan $\mathrm{s}_{3}=$ Sistem Konvensional, sedangkan faktor kedua sebagai sub plot adalah jarak tanam (J) terdiri dari 4 taraf perlakuan, yaitu : $\mathrm{j}_{1}=20 \times 20 \times 40 \mathrm{~cm}, \mathrm{j}_{2}=30 \times 30 \mathrm{x}$ $50 \mathrm{~cm}, \mathrm{j}_{3}=25 \times 25 \mathrm{~cm}$, dan $\mathrm{j}_{4}=30 \times 30 \mathrm{~cm}$. Variabel yang diamati adalah dominasi gulma, tinggi tanaman, jumlah anakan, jumlah anakan produktif, bobot gabah per rumpun, dan bobot 1000 butir gabah kering panen.

Pengambilan sampel gulma dilakukan satu hari sebelum penyiangan, yaitu saat tanaman padi berumur 29 HST dengan menggunakan kuadrat ukuran 50 x 50 
$\mathrm{cm}$. Penghitungan dominasi gulma dilakukan menggunakan analisis SDR (Summed Dominance Ratio) dengan rumus sebagai berikut :

\section{SDR $=($ Kerapatan Nisbi + Frekuensi Nisbi $): 2$}

Keterangan :

Kerapatan mutlak $=\sum$ individu jenis gulma tertentu dalam petak

Kerapatan nisbi $=\frac{\text { Nilai kerapatan mutlak suatu jenis }}{\sum \text { Nilai kerapatan mutlak seluruh jenis }} \times 100 \%$

Frekuensi mutlak $=\frac{\sum \text { plot ditemukan suatu jenis }}{\sum \text { seluruh plot pengamatan }}$

Frekuensi nisbi $=\frac{\text { Nilai frekuensi mutlak suatu jenis }}{\sum \text { Nilai frekuensi mutlak seluruh jenis }} \times 100 \%$ HASIL DAN PEMBAHASAN

\section{Dominasi Gulma}

Hasil pengamatan tercatat ditemukan 7 jenis gulma padi sawah pada ketiga sistem tanam yang digunakan yaitu Cyperus iria L., Eleusine indica L., Fimbristylis miliacea, Limonocharis flave, Ludwigia hyssopifolia G., Monochoria vaginalis, dan Sphenoclea zeylanica G. (Gambar 1). Nilai SDR gulma pada sistem organik disajikan pada Tabel 1. Data pada Tabel 1 menunjukkan bahwa tercatat 3 jenis gulma pada sistem organik dengan nilai SDR tertinggi pada masing-masing jarak tanam yaitu jenis Sphenoclea zeylanica G. Sedangkan nilai SDR gulma pada sistem Tanpa Olah Tanah (TOT) disajikan pada tabel 2. Data pada tabel 2 menunjukkan bahwa tercatat 4 jenis gulma pada sistem TOT dengan nilai SDR tertinggi pada masing-masing jarak tanam yaitu jenis Ludwigia hyssopifolia G. 
Tabel 1. Pengaruh Sistem Tanam dan Jarak Tanam terhadap Nilai Summed Dominance Ratio (SDR) Sistem Organik

\begin{tabular}{|c|c|c|c|c|c|}
\hline \multirow{3}{*}{ No } & \multirow{3}{*}{ Nama Gulma } & \multicolumn{4}{|c|}{$\operatorname{SDR}(\%)$} \\
\hline & & $\mathrm{j}_{1}$ & $\mathrm{j}_{2}$ & $\mathrm{j}_{3}$ & $\mathrm{j}_{4}$ \\
\hline & & $\begin{array}{c}20 \times 20 \times 40 \\
\mathrm{~cm}\end{array}$ & $\begin{array}{c}30 \times 30 \times 50 \\
\mathrm{~cm}\end{array}$ & $\begin{array}{c}25 \times 25 \\
\mathrm{~cm}\end{array}$ & $\begin{array}{c}30 \times 30 \\
\mathrm{~cm}\end{array}$ \\
\hline 1 & $\begin{array}{l}\text { Sphenoclea } \\
\text { zeylanica } \mathrm{G} \text {. }\end{array}$ & $46,19 *$ & $46,53 *$ & $56,35^{*}$ & $58,33^{*}$ \\
\hline 2 & Cyperus iria $\mathrm{L}$. & $11,19 *$ & $27,08 *$ & 9,52 & $18,75^{*}$ \\
\hline 3 & $\begin{array}{l}\text { Ludwigia } \\
\text { hyssopifolia } \mathrm{G} \text {. }\end{array}$ & $42,62 *$ & $26,39 *$ & $34,13 *$ & $22,92 *$ \\
\hline
\end{tabular}

Keterangan: * Gulma yang dominan (jika persentasenya diatas 10\%)

Tabel 2. Pengaruh Sistem Tanam dan Jarak Tanam terhadap Nilai Summed Dominance Ratio (SDR) Sistem TOT

\begin{tabular}{|c|c|c|c|c|c|}
\hline \multirow{3}{*}{ No } & \multirow{3}{*}{ Nama Gulma } & \multicolumn{4}{|c|}{ SDR $(\%)$} \\
\hline & & $\mathrm{j}_{1}$ & $\mathrm{j}_{2}$ & $\mathrm{j}_{3}$ & $\mathrm{j}_{4}$ \\
\hline & & $\begin{array}{c}20 \times 20 \times 40 \\
\mathrm{~cm}\end{array}$ & $\begin{array}{c}30 \times 30 \times 50 \\
\mathrm{~cm}\end{array}$ & $\begin{array}{c}25 \times 25 \\
\mathrm{~cm}\end{array}$ & $\begin{array}{c}30 \times 30 \\
\mathrm{~cm}\end{array}$ \\
\hline 1 & $\begin{array}{l}\text { Sphenoclea } \\
\text { zeylanica } \mathrm{G} .\end{array}$ & (1) & $11,67 *$ & $13,14^{*}$ & - \\
\hline 2 & $\begin{array}{l}\text { Cyperus iria } \\
\text { L. }\end{array}$ & $31,90 *$ & $25,00^{*}$ & $20,20 *$ & $33,04 *$ \\
\hline 3 & $\begin{array}{l}\text { Ludwigia } \\
\text { hyssopifolia } \\
\text { G. }\end{array}$ & $68,10^{*}$ & $63,33 *$ & $55,43^{*}$ & $66,96^{*}$ \\
\hline 4 & $\begin{array}{l}\text { Monochoria } \\
\text { vaginalis }\end{array}$ & - & - & $11,14^{*}$ & - \\
\hline
\end{tabular}

Keterangan : * Gulma yang dominan (jika persentasenya diatas 10\%)

Data nilai SDR gulma pada sistem konvensional disajikan pada tabel 3. Data pada tabel 3 menunjukkan bahwa tercatat sebanyak 5 jenis gulma yang ditemukan pada sistem konvensional dengan nilai SDR tertinggi pada masing-masing jarak tanam yaitu jenis Ludwigia hyssopifolia $\mathrm{G}$. 
Tabel 3. Pengaruh Sistem Tanam dan Jarak Tanam terhadap Nilai Summed Dominance Ratio (SDR) Sistem Konvensional

\begin{tabular}{cccccc}
\hline & & \multicolumn{4}{c}{$\mathrm{SDR}(\%)$} \\
\cline { 3 - 6 } No & Nama Gulma & $\mathrm{j}_{1}$ & $\mathrm{j}_{2}$ & $\mathrm{j}_{3}$ & $\mathrm{j}_{4}$ \\
\cline { 3 - 6 } & $\begin{array}{c}20 \times 20 \times 40 \\
\mathrm{~cm}\end{array}$ & $\begin{array}{c}30 \times 30 \times 50 \\
\mathrm{~cm}\end{array}$ & $\begin{array}{c}25 \times 25 \\
\mathrm{~cm}\end{array}$ & $\begin{array}{c}30 \times 30 \\
\mathrm{~cm}\end{array}$ \\
\hline 1 & $\begin{array}{l}\text { Cyperus iria } \mathrm{L} . \\
22,92^{*}\end{array}$ & $18,94^{*}$ & $58,33^{*}$ & $17,05^{*}$ \\
2 & $\begin{array}{l}\text { Ludwigia } \\
\text { hyssopifolia } \mathrm{G} .\end{array}$ & $52,08^{*}$ & $68,18^{*}$ & $41,67^{*}$ & $82,95^{*}$ \\
3 & $\begin{array}{l}\text { Fimbristylis } \\
\text { miliacea }\end{array}$ & 8,33 & - & - & - \\
4 & $\begin{array}{l}\text { Eleusine indica } \mathrm{L} . \\
\text { Limonocharis }\end{array}$ & 8,33 & $12,88^{*}$ & - & - \\
\hline
\end{tabular}

Keterangan : * Gulma yang dominan (jika persentasenya diatas 10\%)

Keberadaan spesies guma dominan berbeda pada setiap sistem tanam dapat memengaruhi pertumbuhan dan hasil padi, karena kemampuan suatu spesies dalam bersaing mendapatkan unsur hara juga berbeda. Keberadaan Sphenoclea zeylanica G. pada pertanaman padi sawah menurut USDA dilaporkan dapat menyebabkan pengurangan hasil panen hingga 25-50\%, sedangkan keberadaan gulma jenis Ludwigia hyssopifolia $\mathrm{G}$. pada pertanaman padi dapat menyebabkan kehilangan hasil panen sekitar 10-15\% (Sotyati, 2018).
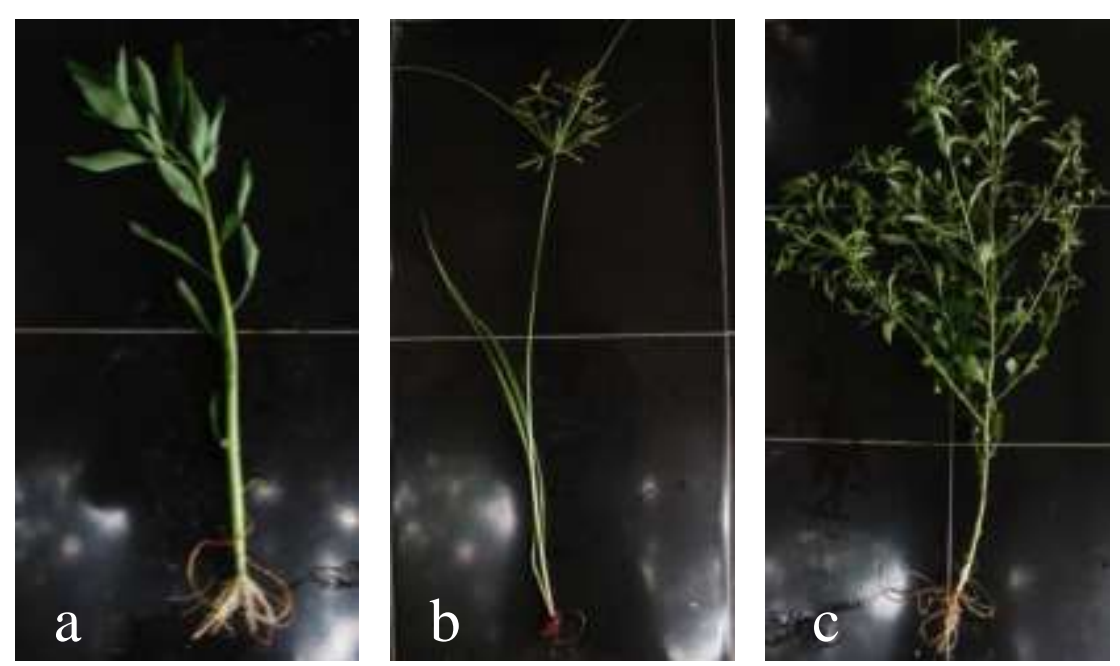

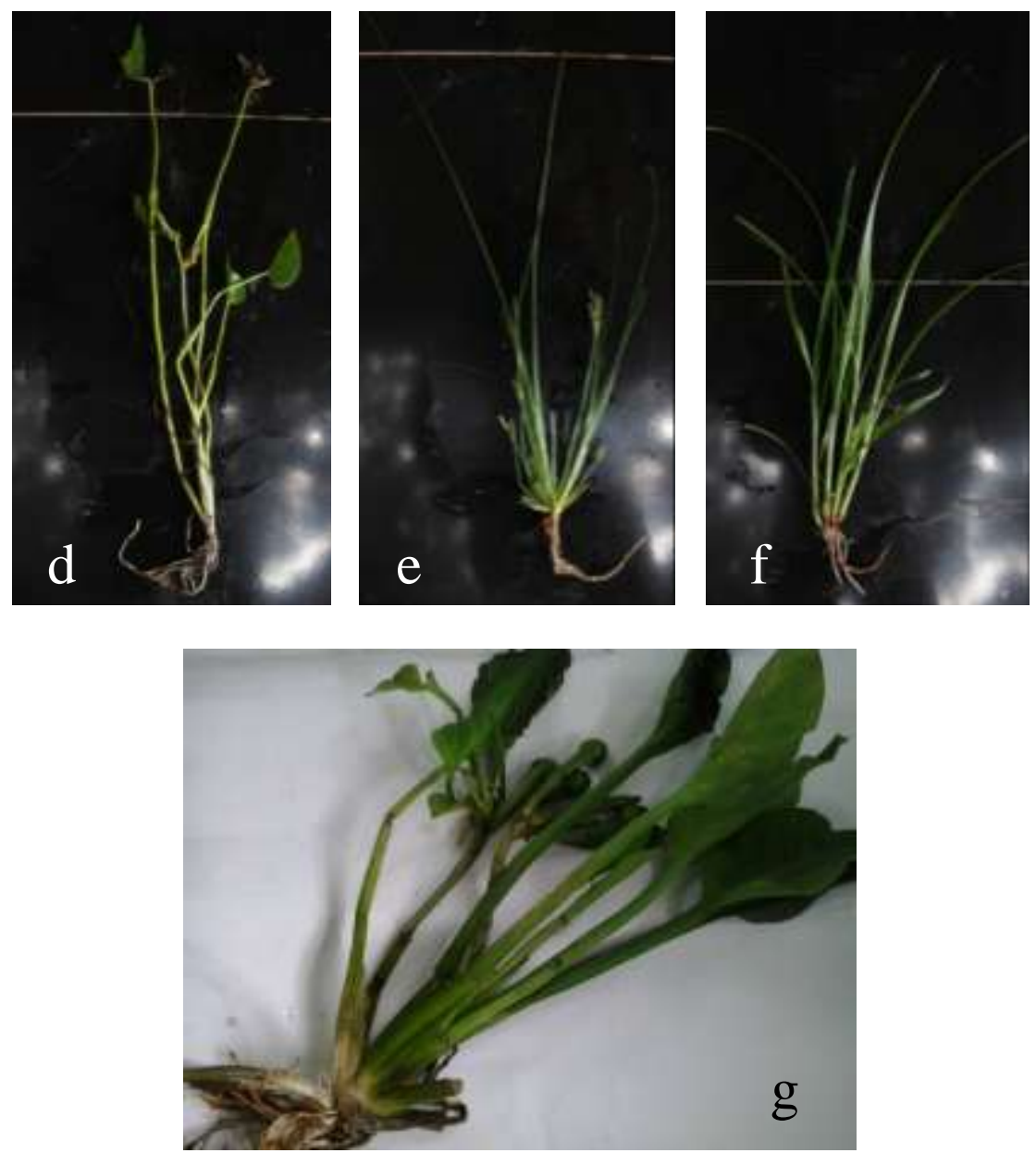

Gambar 1. (a) Sphenoclea zeylanica G. (b) Cyperus iria L. (c) Ludwigia hyssopifolia (d) Monochoria vaginalis (e) Fimbristylis miliacea (f) Eleusine indica L. (g) Limonocharis flava

\section{Tinggi Tanaman}

Tinggi tanaman padi umur 20 HST menunjukkan tidak terdapat interaksi antara sistem tanam dan jarak tanam serta tidak ada pengaruh nyata dari masingmasing perlakuan. Hal tersebut dapat disebabkan karena tanaman padi saat berumur 20 HST masih mengalami masa vegetatif lambat, sehingga meskipun tanaman diberikan perlakuan berbeda tidak akan menyebabkan pertumbuhan yang berbeda nyata, sedangkan pada umur 40 HST dan 60 HST terdapat interaksi dan pengaruh nyata dari masing-masing perlakuan. Pertumbuhan tinggi tanaman umur 60 HST berkorelasi dengan pertumbuhan tinggi tanaman pada pengamatan umur $40 \mathrm{HST}$, dimana pertumbuhan tertinggi didapat pada kombinasi perlakuan $s_{1 j}$, yaitu perlakuan sistem organik dengan jarak tanam 30 x $30 \mathrm{~cm}$. Hal itu karena perlakuan 
tersebut merupakan salah satu anjuran penggunaaan jarak tanam yang baik dalam budidaya padi menurut pedoman pengelolaan tanaman terpadu (PTT), dimana pada jarak tanam 30 × $30 \mathrm{~cm}$, tanaman akan lebih leluasa dalam melakukan peyerapan unsur hara, sinar matahari, dan udara secara optimal, sehingga memberikan kesempatan pada tanaman dalam melakukan pertumbuhannya (Satria, 2017).

Selain itu pada umur 40 HST dan 60 HST pertumbuhan gulma pada masingmasing perlakuan jarak tanam populasinya lebih tinggi dibanding pada pengamatan sebelumnya, sehingga menyebabkan pertumbuhan tanaman padi yang berkompetisi dengan gulma akan terhambat karena gulma lebih banyak menyerap unsur hara dibandingkan dengan tanaman padi (Widayat, 2015). Hal ini menunjukkan bahwa tinggi tanaman merupakan indikator pertumbuhan yang digunakan untuk mengukur pengaruh lingkungan atau perlakuan yang diterapkan, karena tinggi tanaman merupakan ukuran pertumbuhan yang paling mudah dilihat.

\section{Jumlah Anakan}

Hasil pengamatan jumlah anakan menunjukkan bahwa tidak terjadi interaksi antara sistem tanam dan jarak tanam, akan tetapi terdapat pengaruh nyata pada sistem tanam, dimana pada umur 40 HST nilai jumlah anakan pada sistem organik berbeda nyata dengan sistem lainnya. Hal ini dapat disebabkan karena penggunaan input produksi yang diberikan pada sistem organik menggunakan bahan-bahan yang bersifat tidak merusak lingkungan, sehingga tanah pada sistem organik lebih subur karena tidak kehilangan banyak unsur hara, dan hal itu membantu tanaman dalam mencukupi unsur-unsur yang diperlukan untuk pertumbuhannya.

\section{Jumlah Anakan Produktif}

Hasil pengamatan menunjukkan bahwa tidak terjadi interaksi antara sistem dengan jarak tanam terhadap jumlah anakan produktif, dan juga masing-masing perlakuan tidak memberikan pengaruh yang nyata. Perolehan jumlah anakan produktif per rumpun berkaitan erat dengan kemampuan tanaman dalam menghasilkan jumlah anakan, dimana semakin banyak jumlah anakan yang terbentuk, maka akan semakin besar peluang terbentuknya jumlah anakan produktif 
yang kemudian akan menghasilkan malai. Jumlah anakan produktif pada sistem organik mencapai $100 \%$ dari jumlah anakan per rumpun yang dihasilkan sebelumnya, hal ini sesuai dengan pernyataan Lestari (2012) yang menyatakan bahwa jumlah anakan maksimum yang dihasilkan tanaman padi pada lahan organik dapat berpotensi menjadi anakan produktif sepenuhnya. Anakan produktif merupakan anakan yang berkembang lebih lanjut dan akan menghasilkan malai.

Perolehan jumlah anakan produktif akan memengaruhi komponen hasil yang akan dihasilkan selanjutnya. Berbeda dengan sistem organik, pada sistem tanpa olah tanah (TOT) perolehan jumlah anakan produktif jauh lebih rendah dibanding jumlah anakan maksimum yang dihasilkan sebelumnya, hal ini dapat disebabkan karena terdapat 4 jenis gulma yang dominan pada masing-masing perlakuan jarak tanam pada sistem TOT, sehingga menyebabkan persaingan antara tanaman dengan gulma dalam mendapatkan unsur-unsur yang dibutuhkan oleh tanaman dalam masa generatif, yaitu saat tanaman melakukan pengisian bulir pada malai tidak optimal.

\section{Bobot Gabah per Rumpun}

Hasil pengamatan juga menunjukkan bahwa tidak terjadi interaksi antara sistem dengan jarak tanam terhadap bobot gabah per rumpun, dan juga masingmasing perlakuan tidak memberikan pengaruh yang nyata. Hasil ini berkorelasi dengan hasil pengamatan jumlah anakan dan jumlah anakan produktif dan sesuai dengan pernyataan Satria (2017) yang menyatakan bahwa jumlah anakan produktif yang dihasilkan merupakan gambaran dari jumlah anakan maksimum yang dihasilkan sebelumnya, yang kemudian selanjutnya akan berpengaruh terhadap hasil produksi dari tanaman padi.

Hasil pengamatan komponen hasil pada sistem organik tidak sejalan dengan hasil pengamatan pertumbuhan, dimana pada komponen hasil sistem organik mengalami penurunan yang menyebabkan hasilnya tidak berbeda nyata dengan sistem TOT. Hal ini dapat disebabkan karena persaingan antara tanaman dengan gulma dominan jenis Sphenoclea zeylanica G. pada sistem organik lebih tinggi. Hal ini sesuai dengan yang dilaporkan oleh USDA dimana keberadaan jenis gulma ini 
pada pertanaman padi dapat mengurangi hasil panen sekitar 25-50\% (Sotyati, 2018).

\section{Bobot 1000 Butir Gabah Kering Panen}

Sama halnya dengan bobot gabah per rumpun, hasil pengamatan bobot 1000 butir GKP menunjukkan bahwa tidak terjadi interaksi antara sistem dengan jarak tanam dan juga masing-masing perlakuan tidak memberikan pengaruh yang nyata, dan hal ini berkorelasi dengan hasil pengamatan komponen hasil sebeumnya. Akan tetapi rata-rata hasil bobot 1000 butir gabah sudah memenuhi syarat dari deskrips padi Kultivar Cherang yang menghasilkan bobot 1000 butir seberat 27-28 gram (Badan Penelitian dan Pengembangan Pertanian, 2012).

\section{KESIMPULAN}

Terdapat jenis gulma dominan berbeda pada sistem organik, sistem tanpa olah tanah (TOT) dan sistem konevsnional, pada sistem organik jenis gulma dominan yaitu Sphenoclea zeylanica G. (44,38\%), sedangkan pada sistem tanpa olah tanah (TOT) dan sistem konvensional terdapat jenis gulma dominan yang sama secara berturut-turut, yaitu Ludwigia hyssopifolia G. (81,37\%), dan Ludwigia hyssopifolia G. (72,55\%). Selain itu terjadi interaksi antara ketiga sistem tanam dan masing-masing perlakuan jarak tanam terhadap tinggi tanaman umur $40 \mathrm{HST}$, dan tinggi tanaman 60 HST. Serta secara mandiri sistem tanam organik dan penggunaan jarak tanam $30 \times 30 \mathrm{~cm}$ berpengaruh terhadap tinggi tanaman, sedangkan pada komponen hasil masing-masing perlakuan sistem tanam dan jarak tanam menunjukkan hasil tidak berbeda nyata.

\section{DAFTAR PUSTAKA}

Aldrich, R. J. 1984. Weed Crop Ecology Principles in Weed Management. Wadsworth, Inc., Belmont, California, USA. p : 92-126 ; 210-244.

Antralina, Merry. (2012). Karakteristik Gulma dan Komponen Hasil Tanaman Padi Sawah (Oryza sativa L.) Sistem SRI pada Waktu Keberadaan Gulma yang Berbeda. Jurnal Agribisnis dan Pengembangan Wilayah, 3 (2) : 9-17.

Badan Litbang Pertanian, 2012. Varietas Padi Unggulan Badan Litbang Pertanian. http://www.litbang.pertanian.go.id. Diakses tanggal 25 Desember 2017. 
Brown, K., \& K, Brown. 2002. Bushland Weeds: a Practical Guide to their Management, Environmental Weeds Action Network (WA) Inc. Perth WA.

Deptrina, Gita. 2008. Pengaruh Waktu dan Cara Pengendalian Gulma terhadap Pertumbuhan dan Hasil Padi Hibrida (Oryza sativa L.). Skripsi. Institut Pertanian Bogor. Bogor. 59 hlm.

Kementrian Pertanian (2017). Upaya Pemerintah Turunkan Ketergantungan Konsumsi Beras. http://ekonomi.kompas.com/read/2017/10/25/065221726 /upaya-pemerintah-turunkan-ketergantungan-konsumsi-beras.Diakses pada tanggal 21 Januari 2018.

Mercado, L. B.. 1979. Introduction to Weed Science. Publish Sout Asian Regional Centre for Graduate Study and Research.

Sotyati. 2018. Gonda, Gulma Padi yang Jadi Sayuran Bernilai Ekonomis. http://www.satuharapan.com/read-detail/read//gonda-gulma-padi-yang-jadi -sayuran-bernilai-ekonomi. diakses tanggal 26 April 2018.

Satria, B., E.M, Harahap \& Jamilah. 2017. Produktivitas Padi Sawah (Oryza sativa L.) melalui Penerapan Beberapa Jarak Tanam dan Sistem Tanam. Jurnal Agroteknologi FP USU, 5 (3) : 629-637.

Wdayat, D., C.O. Purba. 2015. Produktivitas Tanaman dan Kehilangan Hasil Tanaman Padi (Oryza sativa L.) Kultivar Ciherang pada Kombinasi Jarak Tanam dengan Frekuensi Penyiangan Berbeda. Jurnal Kultivasi, 14 (1) : 17 24. 